\title{
ENTER THE DRAGON
}

\section{Once a poor village, Shenzhen is now one of the wealthiest cities in China. David} Cyranoski learns its plans for the future.

Shenzhen is a city of transformations. Until 1979, it was a small fishing town in southern China. Then in 1980, Communist Party chairman Deng Xiaoping designated Shenzhen, located in Guangdong province just a few miles from Hong Kong, as a 'special economic zone', where tax policies encouraged foreign investment and trade. Since then the city has boomed, with its population growing to 12 million and fishing shacks being razed in favour of towering skyscrapers.

In what came to be known as 'the factory of the world', the city's economy soared to its current gross domestic product (GDP) of 581 billion yuan (US\$76 billion), the fourth largest in China. It produced clothing, shoes and toys quickly and cheaply, and assembled simple electronic goods.

A second transformation is now under way. With active support from local and central government, the city is metamorphosing from contract manufacturer to knowledge producer. The turning point came with the formation of a university town in 2003, comprising graduate schools from three of China's leading academic institutions far to the north: Peking University and Tsinghua University, both in Beijing, and Harbin Institute of Technology in Harbin.

Many academics refer to Shenzhen as 'special' or an 'experiment', Ma Hui, associate dean of the Graduate School at Shenzhen, Tsinghua University, is one. He calls the city both "a window and an open door": its proximity to Hong Kong (see map opposite) can provide a flow of free-market funding and its high profile can show the West how much and how fast China is changing. Just how good the picture from the window will be, and just how wide the door will open, could well depend on how the city manages a balancing act between free-market economy and top-down planning and between basic and applied research.

To create the human resources and technology

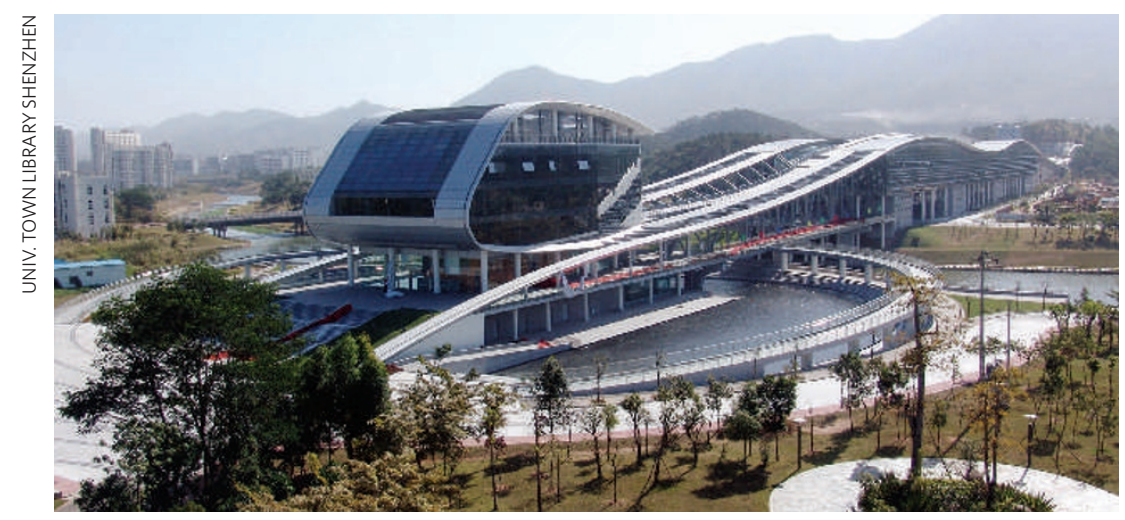

The dragon-shaped library serves as a central point of the University Town campus.

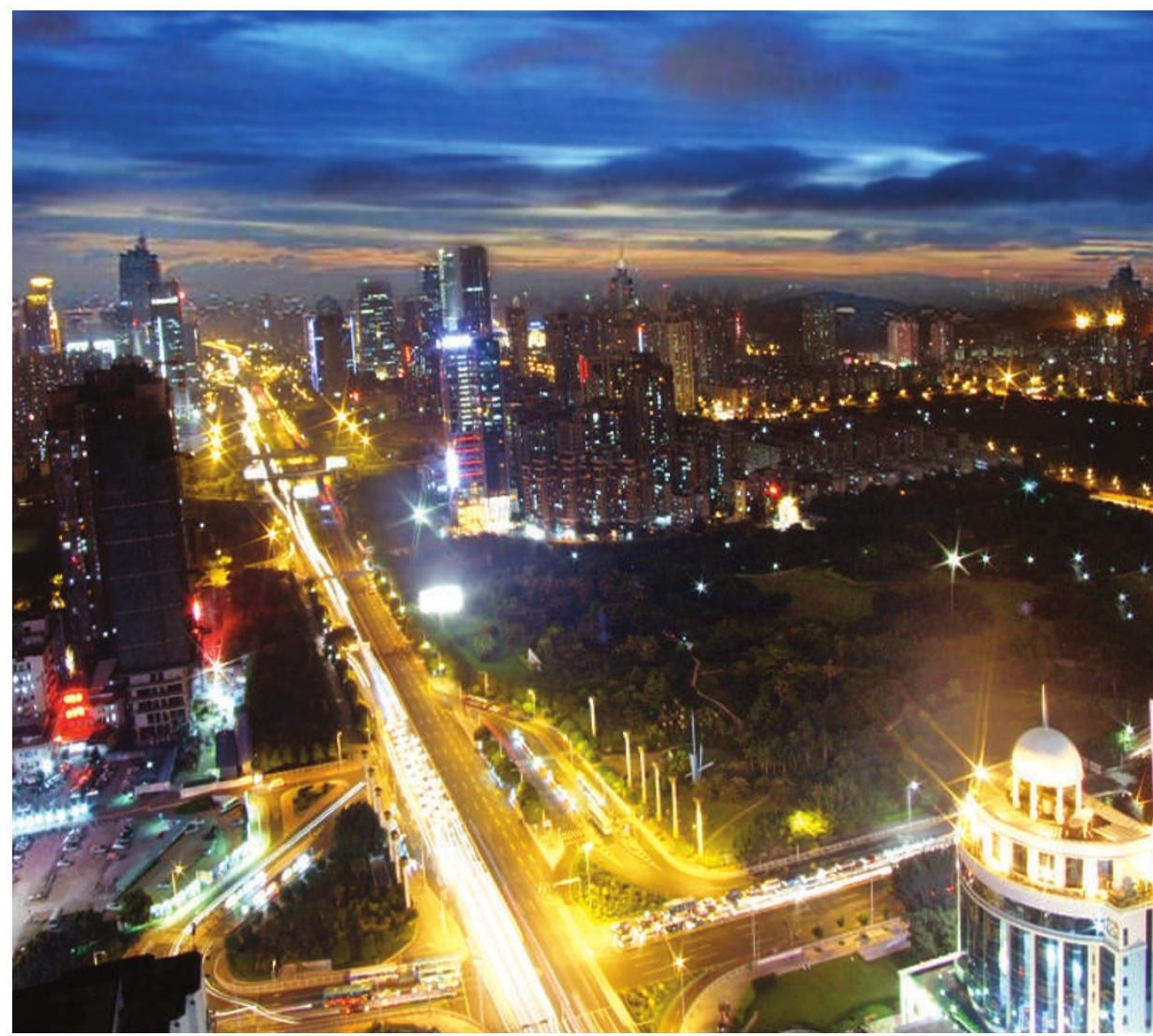

needed by a high-tech city, Shenzhen's policy-makers set about creating a combined science park and university town. Most scientific hubs are based on existing strong research universities, but Shenzhen had no such academic core. So the high-tech industrial park came first, in 1996, led in its early years by Liu Yingli, who subsequently became executive vice-mayor and a key force behind Shenzhen's economic development. Then, in 2001, the city persuaded the graduate schools to set up shop as University Town. Before this, there was just one university, Shenzhen University, which had around 25 graduate students. "That wasn't enough for a modern city," says Zhang Rulin, deputy director of University Town. Of the 4,500 students now studying in University Town, 800 are pursuing PhDs.

\section{Coming home}

Although Shenzhen's declared aim of becoming an international research centre is still a work in progress, increasing numbers of Chinese scientists are coming to Shenzhen from overseas. One is Zhang Yaou, a professor of cellular and molecular biology in the life-sciences division of Tsinghua University's Shenzhen campus. After earning a medical degree in China, she gained research expertise in oncology and haematology in Canada and the United States before moving to Hong Kong, while keeping an eye on China's political and intellectual environment. She's glad she made the move, noting that the Shenzhen students are of the highest quality and as bright as any she's worked with elsewhere.

To ensure these high standards, two-thirds of the teaching staff at the Tsinghua graduate school come from the home institution in Beijing, either residing in Shenzhen or travelling down periodically to teach courses or lead research. The other third mainly comprises returnees like Zhang Yaou. The researchers 
computing, and other interdisciplinary fields, the institute has 600 staff, with plans to grow to 3,000. The director, Fan Jianping, says his three-year term should have the institute stable. "In Shenzhen, if you can build a totally new city in ten years, and a university in six years, you can build an institute in three," he says.

Fan points out of a window in his 200-millionyuan building to a gray five-story building with grime-coated windows only a block away. "Last year this building was just like that," he says. "We are trying to make the blue-collar workers into white-collar workers."

Shenzhen is aiming its sights at converting applied research into saleable products. One of Fan's goals for his institute is patent generation, but the patents must be good. For every three patents applied for, a researcher will be expected to get at least one invention licensed. Tsinghua's Feng comments that, "the big difference with the Beijing main campus is that they have many research achievements, but they don't go to the market. Here they will." Indeed, almost everything in Shenzhen is market-driven, both as an end - commercial products - and in organization and hiring policies.

The Shenzhen Virtual University Park provides continuing education as well as helping start-up businesses. Their curriculum is determined in "market oriented" fashion, says director Yi Yinfa. If the classes are not popular they are dropped. "In Shenzhen there is no 'iron rice bowl' that guarantees permanent employment," says Jin. "Everything is a two- or threeyear contract. We want competition. We want people that are driven for success," he says.

\section{Striking a balance}

Basic science is not neglected, however. In collaboration with the National Orchid Conservation Center in Shenzhen, researchers at the Tsinghua University Shenzhen campus recently discovered and characterized an unknown type of self-pollination used by tree-living orchids in times of drought and lack of wind (Liu, K. W. et al. Nature 441, 945; 2006; a video of the orchid can be seen at natureasia.com/Shenzhen).

Ma thinks that the balance between basic and applied science will change with time. "As we establish ourselves in Shenzhen, we will move more and more upstream towards basic research, always aiming to stay a step ahead of Shenzhen's rapidly evolving high-tech industry," he says. Research is already addressing realworld problems as well. For example, the Cooperative Research and Education Center for Environmental Technology at Shenzhen, funded and staffed jointly by Tsinghua University and Kyoto University in Japan, is looking at ways to provide cleaner water in urban areas.

And Shenzhen already has some role models for applied technology and industry. Telecoms companies Huawei Technologies and Zhongxing Telecom (ZTE) were founded in Shenzhen in the 1980s, and in 2006 brought in 66 billion yuan and 24 billion yuan in

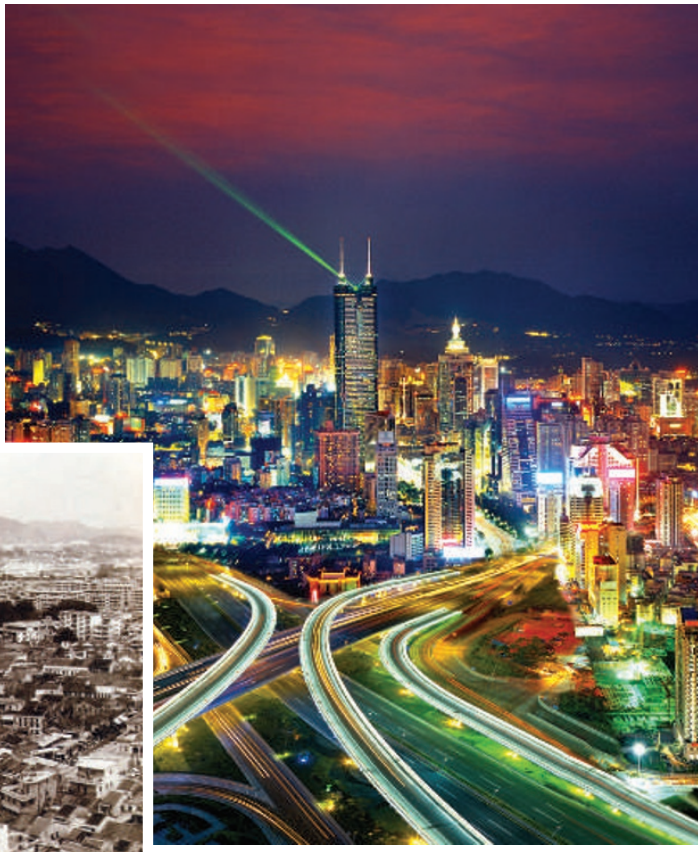

Before and after: Shenzhen's landscape has changed dramatically since 1982 (inset). revenue, respectively. ZTE pours $11.6 \%$ and Huawei $8.2 \%$ of that back into research.

Such companies are helping Shenzhen do something rare for China's booming cities - they are ploughing huge amounts of money back into the local economy. In 2004, Shenzhenbased companies produced more than $50 \%$ of the city's GDP for the first time (by 2006 it was 58\%). In places like Shanghai, 70\% of GDP is produced by foreign investment companies.

"The high-tech industries of Shenzhen's regional innovation system are maturing, and this is setting a strong example for the whole country," says Zhang Jing'an, a member of the Party Leadership Group of the central government's Ministry of Science and Technology and president of the newspaper Science and Technology Daily

(www.stdaily.com). Indeed, governments in developing countries around the world that are trying to build their own special economic zones are looking to Shenzhen as a model.

The city has reinvested its wealth with some headline-catching results. The gene-therapy company SiBiono was set up in Shenzhen in 1998 and had its treatment approved by the Chinese regulatory authorities for head-and-neck squamous cell carcinoma in 2003 (Nature Biotechnol. 22, 3-4; 2004). Some 6,000 people have now been treated. Peng Zhaohui, the company's founder and chairman, says he chose Shenzhen over Shanghai and Beijing because of the financial support offered by the local government.

There are plenty of people to fill spots at these companies - for every successful applicant at Huawei, 99 don't get in. But not enough of them have the right talents. Peng says, "It's hard to get high-level staff. There were no famous universities." Peng ends up recruiting $5 \%$ of his staff from overseas and most of the rest from other parts of China.

The growth of the three universities in University Town will help provide more local talent. The Hong Kong and Shenzhen local governments also agreed this May on greater collaboration in $\mathrm{R} \& \mathrm{D}$ in various areas, including health and environmental protection. "Hong Kong has advantages in attracting international talent and connecting with the international markets," says Zhang Jing'an. "Shenzhen has advantages in developing innovative industries and gathering mainland talent."

But to attract and keep its creative talent, Shenzhen needs to allow room for basic research and intellectual pursuits that don't have immediate economic returns. Given that governments everywhere are increasingly demanding a return on their research investment, Shenzhen's strategy is not so extreme. Still, it remains to be seen whether it can spur the type of Silicon Valley innovation that Shenzhen seeks. But if it can be done, Shenzhen will do it - and in a hurry. 


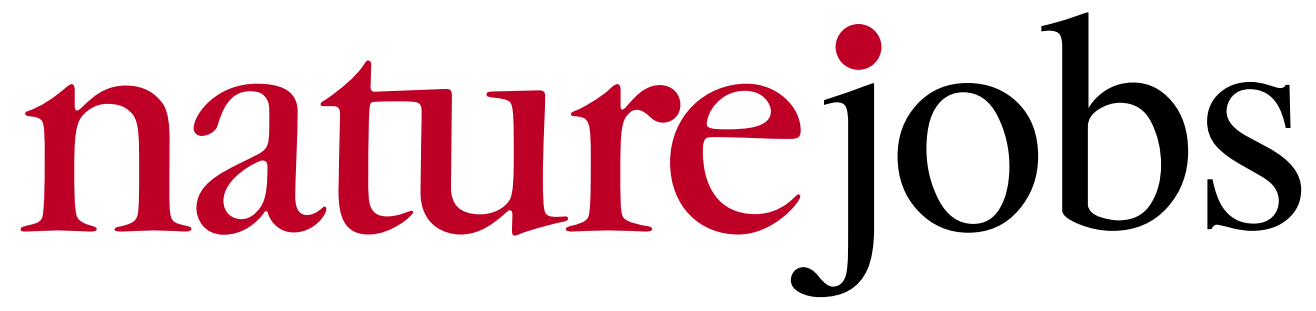

\section{Correction}

In the Regions feature 'Enter the dragon' (Nature 449, 502-504; 2007), we quoted Yi Yinfa as saying that the curriculum at the Shenzhen Virtual University Park is determined in a "market oriented" fashion. This quote should in fact have been attributed to the university park's director, Qiu Xuan. 